\section{Prospective, long-term evaluation of steroid-induced glaucoma}

\begin{abstract}
Purpose To evaluate the intraocular pressure (IOP) after cessation of steroid use in steroid-induced glaucoma and its control with medication or surgery.

Methods Thirty-four eyes of 34 patients having steroid-induced glaucoma were prospectively evaluated after cessation of steroid for IOP, visual acuity, and optic disc status at 3 months, and every 3 months for 18 months. Results Topical steroid use $\mathbf{( 7 3 . 5 \% )}$ was the most frequent cause for glaucoma. The baseline IOP was $35.47 \pm 12.59 \mathrm{mmHg}$. The baseline vertical cup-disc ratio correlated with duration of steroid use $(P=0.014)$ and the baseline IOP $(P<0.0001)$. In 25 patients (73.5\%), IOP could be controlled by topical medications alone, whereas nine patients $\mathbf{2 6 . 5 \% )}$ required surgery. The mean baseline IOP in eyes requiring surgery was $49.67 \pm 13.28 \mathrm{mmHg}$ and in eyes managed medically, $30.36 \pm 7.51 \mathrm{mmHg}(P=0.002)$. The vertical cup-disc ratio in surgically treated patient was $0.87 \pm 0.13: 1$ as compared to $0.71 \pm 0.15: 1(P=0.012)$ in the medically treated group. At 6, 12, and 18 months follow-up, 22 $(64.7 \%), 33(97.1 \%)$, and all $34(100 \%)$ patients were off treatment, respectively.

Conclusions Patients with steroid-induced glaucoma, who were $\leq \mathbf{2 0}$ years old, with a higher IOP, and greater glaucomatous optic neuropathy, were more likely to need surgery. After cessation of steroid therapy, all eyes were off treatment at $\mathbf{1 8}$ months.

Eye (2008) 22, 26-30; doi:10.1038/sj.eye.6702474; published online 23 June 2006
\end{abstract}

Keywords: steroid-induced glaucoma; trabeculectomy

\section{Introduction}

Steroid-induced glaucoma is a form of secondary open-angle glaucoma that is most
R Sihota1, VL Konkal ${ }^{1}$, T Dada1 ${ }^{1}$, HC Agarwal ${ }^{1}$, R Singh ${ }^{2}$ commonly associated with topical application of corticosteroids, but may also result from systemic administration. There are numerous publications on steroid responsiveness ${ }^{1,2}$ but to our knowledge, no prospective study of steroid-induced glaucoma has been conducted. The natural history of steroid-induced glaucoma and the behaviour of intraocular pressure (IOP) after cessation of corticosteroids have been anecdotally recorded. We initiated this pilot study to evaluate the natural course of steroid-induced glaucoma after cessation of steroids.

Patients and methods

A prospective study of consecutive patients diagnosed to have steroid-induced glaucoma at a tertiary-care Glaucoma service was carried out over a period of 1.5 years. Patients with a history of steroid usage, who had at least two of the following three criteria, were recruited for the study: IOP more than $21 \mathrm{mmHg}$ on more than two occasions, glaucomatous optic nerve head changes or glaucomatous visual field defects on Humphrey 30-2 full threshold test. All patients were required to have at least two reliable baseline visual fields (Humphrey 30-2 full threshold) with false-positive rate, falsenegative rate, and fixation losses all below $15 \%$. A visual field defect consisted of at least three contiguous nonedge points on the pattern deviation plot with sensitivity depressed below $P<5 \%$ level out of which one point was depressed below $P<1 \%$ level, reproducible on two consecutive fields. Eyes with a history of ocular trauma or surgery were excluded from the study. A detailed history was taken for the reason for steroid use, the type, dose, and duration of steroid use. The duration of steroid use was also objectively assessed by looking into the medical records of the patient. A family history of glaucoma was also noted. Baseline 
examination included best-corrected visual acuity, slitlamp biomicroscopy, fundus examination, applanation tonometry, gonioscopy, and Humphrey 30-2 full threshold perimetry.

Our institutional review board approved the study, and all participants in the study gave informed consent in accordance with the Declaration of Helsinki.

All steroids were stopped before inclusion of the subjects into the study. Patients having an IOP of less than $40 \mathrm{mmHg}$ were given oral acetazolamide $(5 \mathrm{mg} / \mathrm{kg}$ / dose TDS) for 3 days and simultaneously started on topical antiglaucoma treatment $-0.15 \%$ brimonidine, $0.5 \%$ timolol, or $0.005 \%$ latanoprost alone or in combination depending upon the baseline IOP. If the IOP was $>40 \mathrm{mmHg}$ at presentation, acetazolamide tablets and syrup glycerol $(1 \mathrm{~g} / \mathrm{kg})$ were given together with topical medications to maintain an IOP of less than $20 \mathrm{mmHg}$. During follow-up, some patients having vernal keratoconjunctivitis had an exacerbation of the disease for which loteprednol etabonate $0.5 \%$ BD was used sparingly.

Patients were reviewed at 2 weeks, 4 weeks, 6 weeks, 3 months, and every 3 months thereafter for up to 1.5 years. They were asked to stop systemic acetazolamide and/or glycerol 3 days before each visit. During each visit, Goldmann applanation tonometry, best-corrected visual acuity, and fundus examination were carried out.

Patients who achieved their individualized target IOP, on medication, had their drug therapy tapered until the IOP was controlled without medication, and were then monitored till the end of the study. Trabeculectomy with adjunctive subscleral mitomycin $C$ ( $0.02 \%$ for $3 \mathrm{~min})$ was performed in eyes, where the IOP could not be controlled on maximal topical and systemic

antiglaucoma therapy, in accordance with optic cupping and visual field loss.

Patients with steroid-induced glaucoma were analysed as a whole and were also categorized into groups based on how their IOP was controlled - medications or surgery, as also the mode of steroid administration.

Statistical analysis was performed using descriptive statistics, that is, mean and standard deviation, for the continuous variables, whereas frequency distribution and percentages were calculated for categorical variables. To look for significant differences at particular points of time for continuous variables, Student's $t$-test (unpaired) was applied. $\chi^{2}$ test was used to find associations between the categorical variables. Trend analyses within variables were assessed using two-way ANOVA for both the groups separately. A $P$-value $<0.05$ has been considered statistically significant. SAS 8.0 statistical software has been used for these statistical analyses.

\section{Results}

Thirty-four eyes of 34 patients were included in the present study. The mean age of 34 patients was $28.09 \pm 17.78$ years (range $12-72$ years). The mean baseline visual acuity was $0.68 \pm 0.36$. In five patients $(14.7 \%)$, posterior subcapsular cataracts were present. There were $28(82.4 \%)$ male and six (17.6\%) female patients. All patients had open angles on gonioscopy. The most common cause for steroid use was vernal keratoconjunctivitis (22 patients, 64.7\%). Other indications for steroid therapy were pars planitis (two patients, 5.9\%), bronchial asthma (two patients, 5.9\%), episcleritis, nodular scleritis, choroiditis, interstitial pulmonary fibrosis, eosinophilia, sarcoidosis, alopecia areata, and renal transplant (one patient, $2.9 \%$ each).

Nearly all patients had, at some time, used more than one formulation of corticosteroids. Topical dexamethasone $0.1 \%$ was predominantly used by 18 patients $(52.9 \%)$, followed by oral prednisolone by eight patients $(23.5 \%)$, topical betamethasone $0.1 \%$, subtenon triamcinolone $(20 \mathrm{mg})$, inhalation fluticasone $(250 \mathrm{mcg})$ in two patients $(5.9 \%)$ each, and topical prednisolone 1 and $0.1 \%$ fluromethalone in one patient $(2.9 \%)$ each.

The mean duration of steroid usage was $2.06 \pm 2.45$ years. The mean duration of disease was $3.46 \pm 2.93$ years in eyes that were controlled on antiglaucoma medications, and it was $3.56 \pm 2.73$ years in those that needed surgery $(P=0.933)$ (Table 1$)$. None of the patients gave a positive family history of glaucoma.

The mean vertical cup-disc diameter ratio was $0.78 \pm 0.15: 1$. There was no significant statistical difference in the mean cup-disc ratio of eyes developing steroid-induced glaucoma after being treated by systemic

Table 1 Parameters in steroid-induced glaucoma eyes after stopping steroids

\begin{tabular}{lc}
\hline Parameter & $\begin{array}{c}\text { Mean } \pm S D \\
(\mathrm{n}=34)\end{array}$ \\
\hline IOP & $35.47 \pm 12.59$ \\
Baseline & $17.74 \pm 6.78$ \\
3 months & $15.79 \pm 6.97$ \\
6 months & $13.35 \pm 2.74$ \\
12 months & $12.82 \pm 1.17$ \\
18 months & \\
& \\
Mode of IOP control & $25(73.5 \%)$ \\
Medical & $9(26.5 \%)$ \\
Surgery & \\
& \\
No. of patients off treatment at & $12(35.3 \%)$ \\
3 months & $22(64.7 \%)$ \\
6 months & $33(97.1 \%)$ \\
12 months & $34(100 \%)$ \\
18 months & \\
\hline
\end{tabular}


or local steroids $(P=0.223)$. The baseline cup-disc ratio could be correlated with duration of steroid usage $(P=0.014)$, as also the baseline IOP $(P<0.0001)$.

The mean baseline IOP was $35.76 \pm 12.18 \mathrm{mmHg}$. The baseline IOP in 25 patients who required only medical therapy was significantly lower, $30.36 \pm 7.51 \mathrm{mmHg}$, as compared to the remaining nine patients who underwent surgery, $49.67 \pm 13.28 \mathrm{mmHg}(P=0.002)$. There was no correlation of baseline IOP with duration of steroid use or the age of the patient.

The IOP control after stopping steroids is shown in Table 1 . At 18 months of follow-up, all eyes were off antiglaucoma medications (Figure 1). During follow-up,

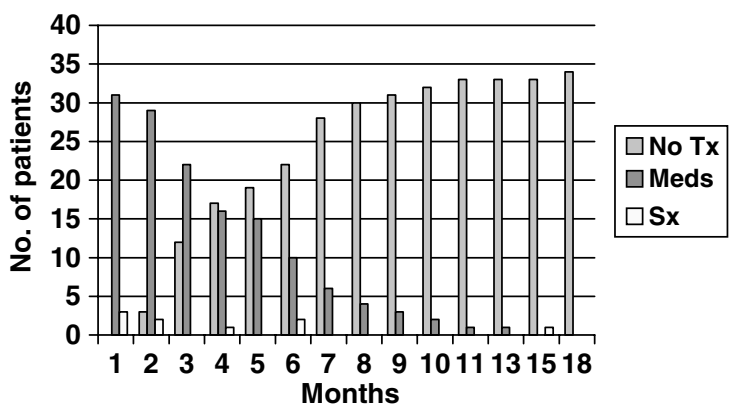

Figure 1 Histogram showing number of patients who underwent surgery, on glaucoma medication, or no treatment. after the initial control of IOP, one patient had an increase in IOP at 15 months, whereas two patients had a spike in IOP after conclusion of the study (follow-up at 28-30 months).

In 25 patients (73.5\%), target IOP could be achieved by antiglaucoma medications alone, whereas nine patients (26.5\%) required surgery (eight patients had vernal keratoconjunctivitis and one patient had choroiditis). The baseline IOP in those eyes, where only medical therapy was necessary to control the IOP, were $30.4 \pm 7.5 \mathrm{mmHg}$, as compared to the eyes that underwent surgery, where the baseline IOP was $49.7 \pm 13.3 \mathrm{mmHg}(P=0.001)$ (Table 2). Evaluating maximum baseline IOP as a predictor for the necessity of a surgical control, it was seen that all eyes with an IOP of $\leq 45 \mathrm{mmHg}$ were controlled on medical management and all eyes except one requiring surgery had a recorded IOP of over $45 \mathrm{mmHg}$.

Twenty-five patients who responded to medical therapy were evaluated for the mode of steroid use. Sixteen patients $(64.0 \%)$ had been on topical steroids and five patients $(20.0 \%)$ on systemic steroids, two patients (8\%) each had received subtenon and inhalational steroids. Of those who underwent surgery, all nine patients were on topical steroids (Table 3).

Of the nine patients who underwent surgery, eight patients had a mixed form of vernal keratoconjunctivitis. All patients who required surgery were $\leq 20$ years of age.

Table 2 Comparison of eyes controlled on medications versus those requiring surgery

\begin{tabular}{|c|c|c|c|}
\hline & $\begin{array}{l}\text { IOP control by medications } \\
\qquad(\mathrm{n}=25)\end{array}$ & $\begin{array}{l}\text { IOP control by surgery } \\
\qquad(\mathrm{n}=9)\end{array}$ & P-value \\
\hline Age (years) & $31.64 \pm 19.61$ & $18.22 \pm 1.39$ & 0.002 \\
\hline Mode of steroid use & & & 0.221 \\
\hline Topical & $20(80.0 \%)$ & $9(100 \%)$ & \\
\hline Systemic & $5(20.0 \%)$ & 0 & \\
\hline Duration of disease (years) & $3.46 \pm 2.93$ & $3.56 \pm 2.73$ & 0.933 \\
\hline Duration of steroid use (years) & $\begin{array}{l}2.26 \pm 2.79 \text { years } \\
\text { (range } 0.25-10)\end{array}$ & $\begin{array}{l}1.49 \pm 0.94 \text { years } \\
\text { (range } 0.50-3.33 \text { ) }\end{array}$ & 0.237 \\
\hline Visual acuity & $0.774 \pm 0.313$ & $0.435 \pm 0.36$ & 0.012 \\
\hline Final IOP & $11.00 \pm 1.41$ & $10.20 \pm 1.23$ & 0.272 \\
\hline C:D ratio & $0.71 \pm 0.15$ & $0.87 \pm 0.13$ & 0.012 \\
\hline \multicolumn{4}{|l|}{ IOP } \\
\hline Baseline & $30.36 \pm 7.51$ & $49.67 \pm 13.28$ & 0.002 \\
\hline 3 months & $16.96 \pm 2.91$ & $19.89 \pm 12.53$ & 0.273 \\
\hline 6 months & $14.88 \pm 2.55$ & $18.33 \pm 13.07$ & 0.207 \\
\hline 12 months & $13.92 \pm 1.47$ & $11.78 \pm 4.55$ & 0.200 \\
\hline 18 months & $12.76 \pm 0.92$ & $13.00 \pm 1.73$ & 0.701 \\
\hline \multicolumn{4}{|l|}{ No. of patients off treatment at } \\
\hline 3 months & $7(28 \%)$ & $5(55.6 \%)$ & 0.138 \\
\hline 6 months & $16(64 \%)$ & $6(66.7 \%)$ & 0.031 \\
\hline 12 months & $25(100 \%)$ & $8(88.9 \%)$ & 0.091 \\
\hline 18 months & $25(100 \%)$ & $9(100 \%)$ & 0.112 \\
\hline
\end{tabular}


Table 3 Comparison of eyes treated with topical steroids versus systemically administered steroids

\begin{tabular}{|c|c|c|c|}
\hline & $\begin{array}{l}\text { Steroid-induced glaucoma } \\
\text { after topical use of steroids } \\
\qquad(\mathrm{n}=27)\end{array}$ & $\begin{array}{l}\text { Steroid-induced glaucoma } \\
\text { after systemic use of steroid } \\
\qquad(\mathrm{n}=7)\end{array}$ & P-value \\
\hline Age (years) & $20.85 \pm 7.7$ & $56.00 \pm 18.47$ & 0.001 \\
\hline Disease duration (years) & $3.25 \pm 2.7$ & $4.38 \pm 3.3$ & 0.357 \\
\hline Duration of steroid use (years) & $1.54 \pm 1.9$ & $4.07 \pm 3.5$ & 0.106 \\
\hline Visual acuity & $0.63 \pm 0.36$ & $0.91 \pm 0.25$ & 0.035 \\
\hline $\mathrm{CD}$ ratio & $0.77 \pm 0.16$ & $0.69 \pm 0.18$ & 0.223 \\
\hline \multicolumn{4}{|l|}{ IOP } \\
\hline Baseline & $37.52 \pm 12.73$ & $29.00 \pm 6.86$ & 0.028 \\
\hline 3 months & $17.81 \pm 7.52$ & $17.43 \pm 2.76$ & 0.896 \\
\hline 6 months & $15.67 \pm 7.74$ & $16.29 \pm 2.69$ & 0.838 \\
\hline 12 months & $13.07 \pm 2.99$ & $14.43 \pm 0.787$ & 0.250 \\
\hline 18 months & $12.85 \pm 1.26$ & $12.71 \pm 0.756$ & 0.786 \\
\hline Mode of IOP control & & & 0.08 \\
\hline - Medical & $18(66.7 \%)$ & $7(100 \%)$ & \\
\hline - Surgery & $9(33.3 \%)$ & 0 & \\
\hline \multicolumn{4}{|l|}{ No. of patients off treatment at } \\
\hline - 3 months & $10(37.0 \%)$ & $2(28.6 \%)$ & 0.676 \\
\hline - 6 months & $19(70.4 \%)$ & $3(42.9 \%)$ & 0.176 \\
\hline - 12 months & $26(96.3 \%)$ & $7(100 \%)$ & 0.605 \\
\hline - 18 months & $27(100 \%)$ & $7(100 \%)$ & 0.232 \\
\hline
\end{tabular}

There was no correlation of duration of steroid use with the necessity for surgery. All patients undergoing surgery had attained their target IOP at the conclusion of the study.

Steroid-induced glaucoma in vernal keratoconjunctivitis (22 patients) was most commonly associated with the mixed form of the disease (14 patients, $63.6 \%$ ), followed by limbal (five patients, 22.7\%) and palpebral (three patients, $13.6 \%)$ forms $(P=0.04)$. The baseline IOP was higher in eyes with vernal keratoconjunctivitis, $38.45 \pm 13.7 \mathrm{mmHg}$, as compared to $30.00 \pm 8.03 \mathrm{mmHg}$ in eyes with other causes of steroid-induced glaucoma $(P=0.03)$.

Latanoprost increased the symptoms and conjunctival congestion in many patients with vernal keratoconjunctivitis and was discontinued and patients were then switched to timolol.

\section{Discussion}

Steroid-induced glaucoma is an iatrogenic secondary open-angle glaucoma, with decreased trabecular outflow causing a rise of IOP. The raised IOP in such eyes has been shown to reduce with time after stopping steroid use, but the time frame for this to happen and baseline factors that help identify eyes that would respond spontaneously and those requiring more aggressive medical therapy or even surgery are not known.
Vernal keratoconjunctivitis was the most common indication for steroid therapy in our series of steroid-induced glaucoma. In smaller retrospective studies of steroid-induced glaucoma, spring catarrh was a common reason for steroid use..$^{3-5}$ Bonini et al ${ }^{6}$ in a long-term review of vernal keratoconjunctivitis recorded a $2 \%$ incidence of steroid-induced glaucoma. There are reports of other, less common causes of steroid-induced glaucoma, for example, after radial keratotomy, ${ }^{7}$ intravitreal triamcinolone acetonide, ${ }^{8}$ after subtenon injection of triamcinolone acetonide during uveitis, ${ }^{9}$ after a scleral reinforcement procedure, ${ }^{10}$ following renal transplant, after application of steroid cream over eyelid skin, inhalers, etc.

Our study showed that the mixed form of vernal keratoconjunctivitis was most commonly associated with steroid-induced glaucoma, followed by the limbal form, and least with the palpebral variety. The palpebral form has been the most frequently reported in a large series of vernal keratoconjunctivitis. ${ }^{11}$

Our patients had a mean age of 28.09 years \pm 17.78 , possibly due to the large number of patients having vernal keratoconjunctivitis, that usually affects younger patients. ${ }^{11,12} \mathrm{~A}$ male preponderance was seen in our study, both in patients having vernal keratoconjunctivitis as well as in patients with other reasons for steroid use, probably reflecting a greater steroid responsiveness in males. Our study corroborates the finding of frequent use of topical dexamethasone and betamethasone as a cause 
of steroid-induced glaucoma as reported in previous studies. $^{3,4}$

In our study, the mean duration of steroid use was $2.06 \pm 2.45$ years and the duration of steroid use could be correlated with a larger cup-disc ratio, but not with baseline IOP or the necessity for surgery. The duration of steroid use was significantly longer in patients using systemically administered steroids. In a study by Mohan et $a l^{4}{ }^{4} 63.6 \%$ patients used steroids for more than 1 year. Munjal et $a l^{3}$ found that $64.29 \%$ of patients having steroid-induced glaucoma used steroids for 1 or more years. Godel et $a l^{13}$ noted that the duration of treatment with systemic steroids was not associated with the rise in IOP. Espildora et al ${ }^{14}$ studied 22 patients with cortisone-induced glaucoma and reported that patients who had instilled the medication for less than 8 weeks recovered normal ocular pressure after discontinuation of the corticoid. On the contrary, those who had employed the corticoid for more than 4 years did not regain normal ocular tension, and medical treatment, or even surgical therapy in a large number of cases, had to be employed. Thus, a prolonged use of steroids seems to lead to greater ocular damage.

The vertical cup-disc ratio in our study could be correlated with the baseline IOP. The baseline mean IOP in our patients was $35.47 \pm 12.59 \mathrm{mmHg}$, with a maximum of $64 \mathrm{mmHg}$. The baseline IOP was significantly higher in patients using topical steroids, patients with a mixed form of vernal keratoconjunctivitis, and those who underwent surgery. Mohan et al found 10 of 44 steroid-induced glaucoma eyes to have an IOP of more than $40 \mathrm{mmHg}$.

In the present study, IOP could be controlled in all patients with medical or surgical therapy by the end of the study. At the end of 6 months, 22 of 34 patients $(64.7 \%)$ were off antiglaucoma treatment, and all eyes were off treatment by 18 months. During follow-up after 12 months, three patients had an increase in IOP. This may reflect a decrease in aqueous outflow with age in a trabecular meshwork which is already compromised or an unmasking of primary open-angle glaucoma and indicates a need for a long-term vigilance in these patients. Mohan et $a l^{4}$ found that 12 of 14 eyes studied retrospectively appeared to have a controlled IOP at 4 weeks without medication.

Latanoprost, brimonidine, or beta-blockers were prescribed in this study. Patients were more comfortable with the latter two. Latanoprost was not well tolerated in patients with vernal keratoconjunctivitis and thus should not be used as an ocular hypotensive in these patients. Scherer et $a l^{15}$ have reported a $28 \%$ decrease in IOP with latanoprost in eyes having steroid induced glaucoma.

Surgery was performed in nine of 34 patients $(26.5 \%)$ in this study. A previous study of juvenile glaucomas found that four of 11 steroid glaucoma eyes (36.6\%) required surgery. ${ }^{5}$ Honjo et $a l^{16}$ did a study on external trabeculotomy for the treatment of steroid-induced glaucoma, with a surgical success of $83.6 \%$ at 5 years.

In conclusion, after cessation of steroid therapy, 22 patients $(64.7 \%)$ could be taken off the treatment in 6 months, and all at the end of the study. Patients who were $\leq 20$ years old, with a higher IOP and greater glaucomatous optic neuropathy were more likely to need surgery. After cessation of steroid therapy, all eyes were off treatment at 18 months. Supervision for long periods is essential, as the IOP may rise even after initial control after cessation of steroids.

\section{References}

1 Francois J. Corticosteroid glaucoma. Ophthalmologica 1984; 188: 76-81.

2 Armaly MF. Cortisone glaucoma. Ophthalmologica 1970; 161: 418-422.

3 Munjal VP, Dhir SP, Jain IS. Steroid induced glaucoma. Indian J Ophthalmol 1982; 30(4): 379-382.

4 Mohan R, Murlidharan AR. Steroid induced glaucoma and cataract. Indian J Ophthalmol 1989; 37(1): 13-16.

5 Sihota R, Sood N N, Agarwal H C. Juvenile secondary glaucomas. J Glaucoma 1993; 15: 80-84.

6 Bonini S, Bonini S, Lambiase A, Marchi S, Pasqualetti P, Zuccaro $\mathrm{O}$ et al. Vernal keratoconjunctivitis revisited. Ophthalmology 2000; 107(6): 1157-1163.

7 Sasaki R, Suda K, Fukuchi T, Nakatsue T, Funaki S, Ohta A et al. A case of steroid-induced glaucoma after radial keratotomy. Jpn J Ophthalmol 2003; 47(5): 534.

8 Jonas JB, Kreissig I, Degenring R. Secondary chronic open-angle glaucoma after intravitreal triamcinolone acetonide. Arch Ophthalmol 2003; 121(5): 729-730.

9 Bui Quoc E, Bodaghi B, Adam R, Burtin T, Cassoux N, Dreifuss $\mathrm{S}$ et al. Intraocular pressure elevation after subtenon injection of triamcinolone acetonide during uveitis. J Fr Ophtalmol 2002; 25(10): 1048-1056.

10 Park JJ, Gole GA. Corticosteroid-induced glaucoma in a child after a scleral reinforcement procedure. Clin Exp Ophthalmol 2002; 30(5): 372-374.

11 Neumann E, Gutmann MJ, Blumenkrantz N, Michaelson IC. A review of four hundred cases of vernal conjunctivitis. Am J Ophthalmol 1959; 47: 166-172.

12 Khan MD, Kundi N, Saeed N, Fulab A, Anisa F. Incidence of keratoconus in spring catarrh. Br J Ophthalmol 1988; 72: 41-43.

13 Godel V, Feiler-Ofry V, Stein R. Systemic steroids and ocular fluid dynamics. I Analysis of the sample as a whole; influence of dosage and duration. Acta Ophthalmol 1972; 50: 655.

14 Espildora J, Vicuna P, Diaz E. Cortisone-induced glaucoma: a report on 44 affected eyes. J Fr Ophtalmol 1981; 4(6-7): 503-508.

15 Scherer WJ, Hauber FA. Effect of latanoprost on intraocular pressure in steroid-induced glaucoma. J Glaucoma 2000; 9(2): 179-182.

16 Honjo M, Tanihara H, Inatani M, Honda Y. External trabeculectomy for the treatment of steroid induced glaucoma. J Glaucoma 2000; 9(6): 483-485. 